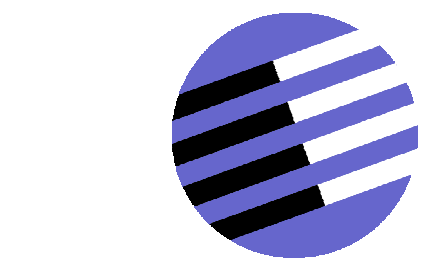

GOVERNANCE AND THE EFFICIENCY

OF ECONOMIC SYSTEMS

G ES Y

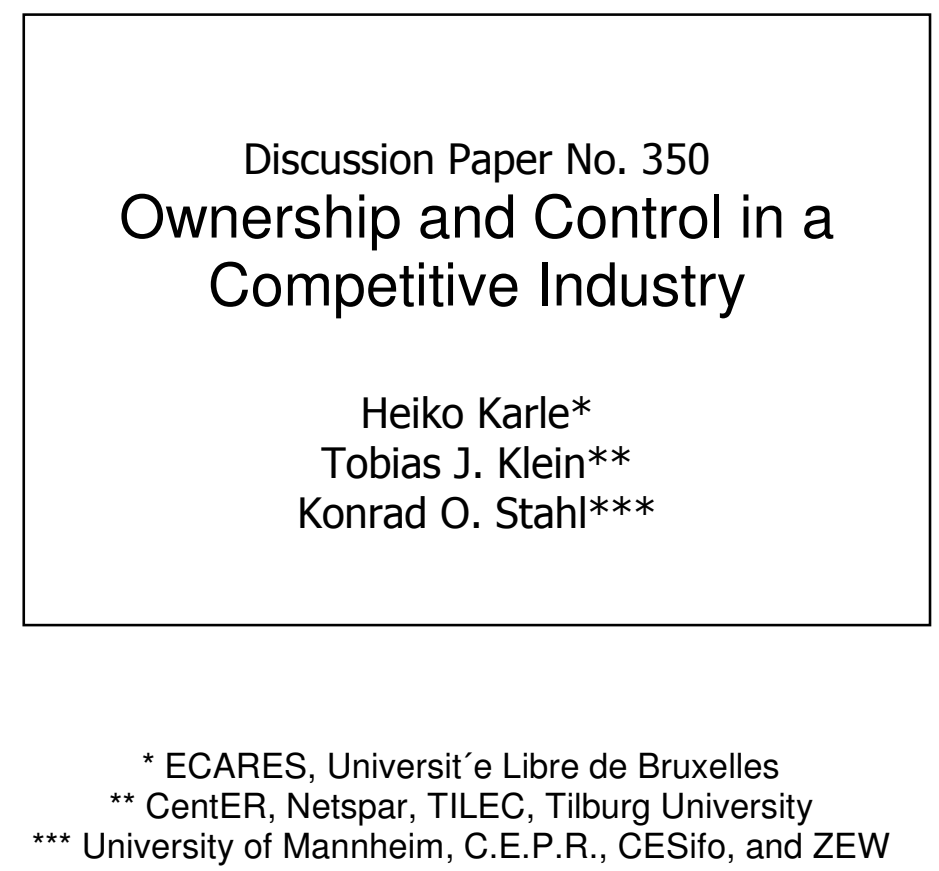

February 2011

Financial support from the Deutsche Forschungsgemeinschaft through SFB/TR 15 is gratefully acknowledged. 


\title{
Ownership and Control in a Competitive Industry*
}

\author{
Heiko Karle $\quad$ Tobias J. Klein $\quad$ Konrad O. Stahl ${ }^{\dagger}$
}

February 21, 2011

\begin{abstract}
We study a differentiated product market in which an investor initially owns a controlling stake in one of two competing firms and may acquire a non-controlling or a controlling stake in a competitor, either directly using her own assets, or indirectly via the controlled firm. While industry profits are maximized within a symmetric two product monopoly, the investor attains this only in exceptional cases. Instead, she sometimes acquires a noncontrolling stake. Or she invests asymmetrically rather than pursuing a full takeover if she acquires a controlling one. Generally, she invests indirectly if she only wants to affect the product market outcome, and directly if acquiring shares is profitable per se.
\end{abstract}

JEL Classification: L13, L41.

Keywords: Differentiated products, separation of ownership and control, private benefits of control.

\footnotetext{
${ }^{*}$ We are grateful to Patrick Bolton, Mathias Dewatripont, Klaus Ritzberger, Lars-Hendrik Roeller, Yossi Spiegel and Elu von Thadden for insightful discussions, and to various seminar and conference audiences for helpful comments and suggestions.

${ }^{\dagger}$ H. Karle: ECARES, Université Libre de Bruxelles; T. J. Klein: CentER, Netspar, TILEC, Tilburg University; K. O. Stahl: University of Mannheim, C.E.P.R., CESifo, and ZEW. E-Mail for correspondence: kos@econ.uni-mannheim.de.
} 


\section{Introduction}

A firm, especially if large, is typically owned by more than one investor. With her stake, such an investor may or may not control that firm's allocation decisions. If controlling, she may impose her personal objectives onto the firm. For instance, if she owns a stake in a competitor, then she may force the firm controlled by her to account for the competitor's profit when maximizing its own. In this paper, we rigorously analyze both, such an investor's incentives to acquire a controlling or non-controlling stake in a competitor, and the resulting allocation in the industry.

Towards that, consider the simplest possible set up: an institution-free economy involving a symmetric duopoly in differentiated products, in which industry profits are maximized at a symmetric two product monopoly. One of the two firms is controlled by a block holder, who may acquire property rights in the competitor either via cash flow rights, i.e. the right to absorb the profits generated by the competing firm in the proportion of the shares acquired; and/or control rights, i.e. the right to control the competitor's strategies.

Within this simple setup, one expects first that the block holder is always interested in acquiring controlling cash flow rights rather than non-controlling ones; and that she acquires all cash flow rights from both firms in order to establish, and internalize, the symmetric two product monopoly maximizing industry profits.

Second, one expects that, rather than using her own funds, she acquires those rights in the other firm all through the firm controlled by her-at least if she does not fully own that firm. This is because via such an indirect acquisition she gains control over the competitor at just a fraction of the acquisition costs determined by her interest in the acquiring firm.

We show, however, that even in the institution-free environment considered here, full monopoly is not necessarily the outcome generated by the active investor. Her acquisition decisions do generally not result in full ownership of both firms. There are regimes in which she does not even acquire a controlling stake in the competitor, but prefers to acquire a non-controlling one. The general reason is that the allocation incentives are eventually dominated by the redistribu- 
tion of rents in the acquisition process, and these are dependent on the firms' initial ownership structures.

Towards arriving at these results, we consider a parsimoniously specified two-stage model, which we solve by backward induction. We characterize equilibrium prices and reduced form profits of the two firms in the second stage. We pay particular attention to the fact that the objectives to be maximized vary with the cash flow and/or controlling interests in the other firm of an investor initially controlling one of the firms, and how this affects prices and profits.

In the first stage of the game the active investor's acquisition decisions are determined. As to the initial ownership of the remaining shares in the two firms, we distinguish between two polar cases, namely that the shares in the target firm and/or the remaining shares in the firm already controlled are held by either one block holder, or by very small dispersed shareholders. In the former case, the block holder of shares in the target firm is pivotal when it comes to the acquisition of ownership and control rights. In the latter case, each small shareholder is essentially non-pivotal. Our analysis of the acquisition stage of the game is thus conditioned on four combinations of initial ownership structures involving the two firms. For reasons justified below, we keep exogenous the critical fraction of shares needed to acquire control over the target firm.

In our model, asymmetric initial ownership structures generate asymmetric equilibrium outcomes in the acquisition game - the reason being that acquiring shares from the pivotal block holder involves positive acquisition gains to the active investor, while in equilibrium, the nonpivotal shareholders absorb all acquisition gains. It is, however, surprising to see that equilibrium outcomes may be asymmetric under symmetric initial ownership, and that the acquisition game does not necessarily result in a monopoly in which both firms are owned by the active investor. We explicitly model the product market impacts of the acquisition decisions and can therefore distinguish between acquisition gains originating from product market outcomes favorable to the shares initially held by the investor, and acquisition gains to our investor from the acquired shares per se. 
This has a direct bearing on the mode of acquisition: When there are no gains from the acquired shares per se, and the acquisition purely affects the profitability of her inherited shares, one would expect that the investor chooses to acquire indirectly via the controlled firm; and by contrast, that she acquires directly using her own funds whenever gains from acquiring shares per se can be realized, in order not to share these acquisition gains with the residual owners of the controlled firm. In other words, she always acquires indirectly from dispersed shareholders, and directly from block holders. Yet this is not the case. While the realization of gains from acquired shares per se remains the driving force for direct acquisitions, it is not the case that acquisitions from block holders are always profitable. In particular, under a symmetric ownership structure involving two block holders, the equilibrium outcome is not necessarily full monopoly under the active investor's exclusive ownership.

While our model set up is very parsimonious, we claim that the forces exposed here have an important bearing on regulatory and competition policy. As to regulatory policy, we emphasize that minority shareholder exploitation is a major issue exposed in this analysis. As to competition policy, the results expose in particular that not only controlling, but also non-controlling cash flow rights effectuate allocation decisions. This should add to competition policy concerns, as competition policy traditionally focuses on control rights. ${ }^{1}$

The remainder of the paper is organized as follows. In the following Section 2, we present the model. We characterize product market outcomes in Section 3. In Section 4, we discuss outcomes of the acquisition game, and extensions in Section 5. It turns out to be instructive to relate our findings to the literature only in Section 6. We conclude with Section 7. All proofs can be found in the Appendix.

\footnotetext{
${ }^{1}$ Patterns are also quite startling when considering ownership and control patterns across vertically related firms, which Röller and Stahl (2010) analyze in a companion paper.
} 


\section{The Model}

Our industry consists of two firms $i \in\{A, B\}$ selling substitutes. The firms are succinctly characterized by twice differentiable reduced form payoffs $\pi_{i}\left(p_{A}, p_{B}\right), i=A, B$ that are supposed to satisfy Assumption

(i) $\pi_{A}(x, y)=\pi_{B}(y, x) \forall x, y \geq 0$.

(ii) $\partial \pi_{i}\left(p_{A}, p_{B}\right) / \partial p_{j}>0, i, j=A, B, j \neq i$.

(iii) $\partial^{2} \pi_{i}\left(p_{A}, p_{B}\right) / \partial p_{i}^{2}<0, \partial^{2} \pi_{i}\left(p_{A}, p_{B}\right) / \partial p_{j}^{2} \leq 0, i, j=A, B, j \neq i$.

(iv) $\partial^{2} \pi_{i}\left(p_{A}, p_{B}\right) / \partial p_{i} \partial p_{j}>0,\left|\partial^{2} \pi_{i}\left(p_{A}, p_{B}\right) / \partial p_{i}^{2}\right|>\partial^{2} \pi_{i}\left(p_{A}, p_{B}\right) / \partial p_{i} \partial p_{j}, i, j=A, B, j \neq i$.

(v) $\pi_{A}\left(p_{A}, p_{B}\right)+\pi_{B}\left(p_{A}, p_{B}\right)$ is maximal at symmetric monopoly prices $p_{A}=p_{A}^{M}=p_{B}=p_{B}^{M} \equiv$ $p^{M}$.

Assumption (i) ensures complete symmetry between the two firms. It is helpful in allowing us to isolate the effects of changes in ownership arrangements on prices and profits. Assumption (ii), and the first part of Assumption (iii) are standard. The second part of Assumption (iii) is needed for the second order conditions for optimization in the interfirm interactive situation considered here to be satisfied. The first part of Assumption (iv) is again standard. Its second part states intuitively that the effect of a change in its own price $p_{i}$ on the marginal profits of firm $i$ is stronger than the effect of a price change in the competing firm. ${ }^{2}$ Finally, with Assumption (v), we rule out that the active investor prefers to shut down one of the two firms when controlling both, in order to reduce fixed costs. The issue of firm shut down arises in our model if products are sufficiently close substitutes and fixed costs per firm (or product) are sufficiently high. This situation is analyzed in the extensions section.

\footnotetext{
${ }^{2}$ Prices as determinants of firms' payoffs are used only as specific objects. Our model results hold for any instruments whose use satisfies strategic complementarity. A key example would be investment.
} 
In our analysis, we focus on acquisition decisions that are driven only by market power considerations. We abstract from efficiency considerations, in particular from economies of scope that also may have a bearing on merging the two firms under one controlling owner.

As to the initial ownership structures involving the two firms: Each firm's share volume is normalized to unity. Firm $A$ is initially controlled by some investor $I$ (she) who holds a block $\alpha_{A}=\alpha_{A}^{0} \in(0,1]$. Neither investor $I$ nor firm $A$ are assumed to hold initial stakes in firm $B$.

The rest of firm $A$ and the whole of firm $B$ are assumed to be either owned by many equally sized small investors, or by another large investor $I_{A}$ and $I_{B}$, respectively. In the latter case, $I_{B}$ also controls firm $B$ 's allocation decisions. Neither investor $I_{B}$ nor firm $B$ are assumed to be initially invested in firm $A$.

The cases involving firm ownership patterns considered here are summarized in the following table.

\begin{tabular}{lcc}
\hline \hline & Shares of $B$ dispersed & Shares of $B$ concentrated \\
\hline Remaining shares of $A$ dispersed & 1 & 3 \\
Remaining shares of $A$ concentrated & 2 & 4 \\
\hline \hline
\end{tabular}

The first stage of our two stage model involves the acquisition of shares. Only investor $I$ is assumed to be willing and able to acquire shares in firm $B$, or to acquire additional shares in firm $A$. Neither investor $I_{B}$ nor firm $B$ are assumed to become active by investing. ${ }^{3}$

Now, the controlling block holder $I$ in firm $A$ can either directly acquire a stake $\alpha_{B}$ in firm $B$; or, by virtue of controlling firm $A$, induce firm $A$ to acquire indirectly a stake $\gamma$ in firm $B$; or a convex combination thereof. This is illustrated in Figure 1. Both investor $I$ and firm $A$ are assumed to be financially unconstrained. The opportunity costs of their funds are normalized to

\footnotetext{
${ }^{3}$ This assumption is clearly restrictive. We conjecture in Section 7 what would happen if we did not make it. For now, it is used to reduce the complexity of the allocation decisions involved. Clearly, it will be interesting to study this in more detail in future work.
} 


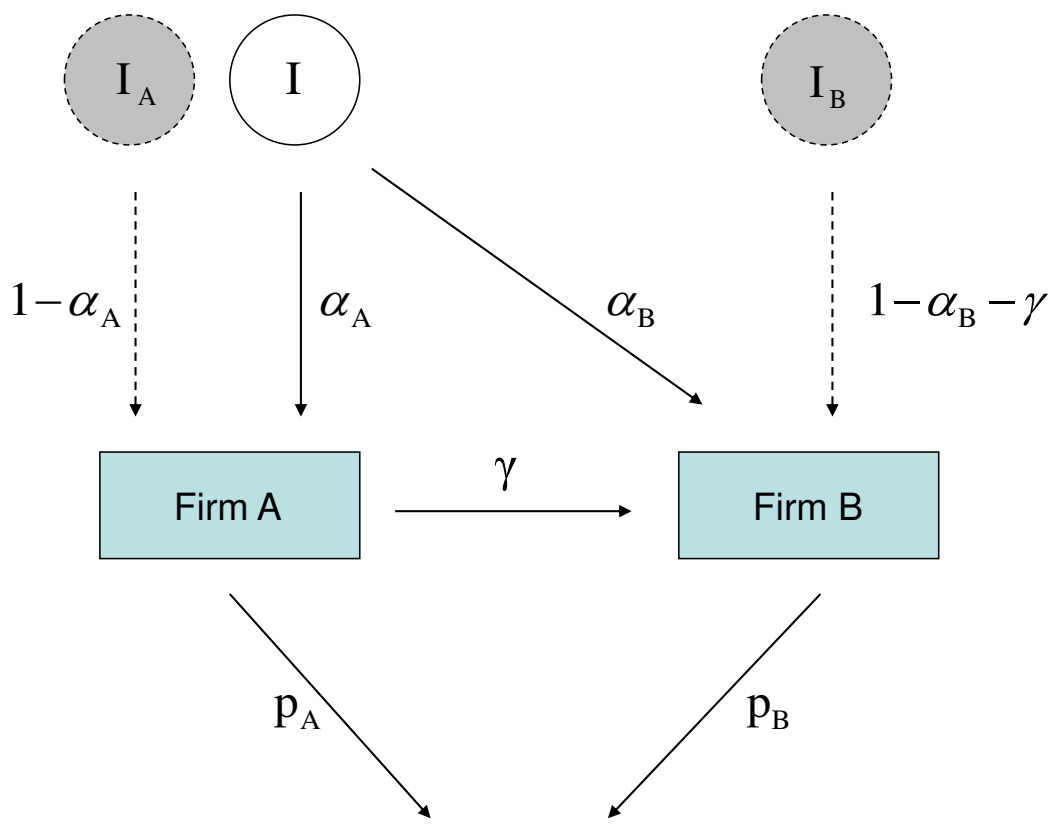

Product Market

Figure 1: Ownership structures.

zero.

Investor I's cash flow interest in $B$ is denoted by $\tilde{\alpha}_{B} \equiv \alpha_{B}+\alpha_{A} \gamma$, where $\alpha_{A}$ denotes the quantity of shares she holds in firm $A$. I is supposed to control firm $B$ if she acquires at least a fraction $\tilde{\alpha}_{B}=\hat{\alpha}_{B}$ of firm $B$ 's shares. Since $I$ has a controlling interest already in firm $A, I$ controls $B$ if $\alpha_{B}+\gamma \geq \hat{\alpha}_{B}$, i.e. even if $\tilde{\alpha}_{B}<\hat{\alpha}_{B} \cdot{ }^{4}$

In the second stage of the game the two firms' prices are determined. If a firm is owned by dispersed shareholders, its management is supposed to maximize the firm's profit in the usual way. In contrast, if controlling shares of that firm are owned by a block holder, that block holder,

\footnotetext{
${ }^{4}$ A natural sufficient condition for control is that she owns more than 50 per cent of the shares. Yet this condition is by no means necessary. We have conducted field studies suggesting that the percentage of shares sufficient for control tends to be much smaller. In fact, the size of the controlling stake depends on the distribution of the firm's ownership. If it is otherwise dispersed, then a block holding as small as 5 per cent is sufficient for control. This stylized fact obtained from field studies is also supported by shareholder voting theory, see Ritzberger (2005).
} 
after deciding about the direct or indirect acquisition of stakes in both firms, uses the price(s) of the firm(s) controlled by her to maximize the sum of profits in both firms weighed by her cash flow interests in these firms.

The timing in our model is as follows.

1. Investment: $I$ decides whether or not to buy an additional stake $\alpha_{A}-\alpha_{A}^{0}$ in firm $A$, and a stake in firm $B$. The latter may be a stake $\alpha_{B}$ acquired directly or, via firm $A$, an indirectly acquired stake $\gamma$ with associated cash flow rights $\alpha_{A} \gamma$. They are non-controlling if $\alpha_{B}+\gamma<\hat{\alpha}_{B}$, and controlling if $\alpha_{B}+\gamma \geq \hat{\alpha}_{B}$.

2. Pricing: If $\alpha_{B}+\gamma<\hat{\alpha}_{B}$, so that $I$ does not control firm $B, I$ sets $p_{A}$ so as to maximize $\alpha_{A} \pi_{A}\left(p_{A}, p_{B}\right)+\tilde{\alpha}_{B} \pi_{B}\left(p_{A}, p_{B}\right)$ for given $p_{B}$. In turn, firm $B$ 's management (or controlling owner) sets price $p_{B}$ so as to maximize $\pi_{B}\left(p_{A}, p_{B}\right)$.

If $\alpha_{B}+\gamma \geq \hat{\alpha}_{B}$, so that $I$ does control $B, I$ sets both $p_{A}$ and $p_{B}$ so as to maximize $\alpha_{A} \pi_{A}\left(p_{A}, p_{B}\right)+\tilde{\alpha}_{B} \pi_{B}\left(p_{A}, p_{B}\right)$.

3. Payoff: $I$ obtains $\alpha_{A} \pi_{A}\left(p_{A}, p_{B}\right)+\tilde{\alpha}_{B} \pi_{B}\left(p_{A}, p_{B}\right)$, less the acquisition price of her additional stakes in $A$ and $B$. The remaining owners of $A$ and $B$ obtain the fraction of $\pi_{A}\left(p_{A}, p_{B}\right)$ and $\pi_{B}\left(p_{A}, p_{B}\right)$, respectively, that corresponds to their share holdings.

Our equilibrium concept is sub-game perfection, so that this game is solved by backward induction. If $I$ holds non-controlling shares in firm $B$, an equilibrium in the product market obtains at prices so that both $I$ and firm $B$ (representing managers and owners) cannot increase their profit, given the price quoted by the opponent. If $I$ controls firm $B$, then the equilibrium corresponds to the maximum of the sum of the two firms' profits, weighed by I's share holdings. An equilibrium in the market for shares is obtained if $I$ cannot initiate another trade acceptable to the shareholder community that is beneficial to her.

In the acquisition decisions discussed here, investor I may be indifferent between a number of alternatives. In order to reduce that indifference set, we invoke a final simplifying but plausi- 
ble assumption, namely that there is a (small) transactions cost proportional to the transactions volume, and thus amongst the alternatives $I$ is indifferent she picks the one with the lowest associated transactions volume.

\section{Product Market Stage}

We now characterize how product market equilibrium prices and profits depend on I's cash flow rights in $B$, separately for the case in which $I$ does not control firm $B$, and the case where she does.

Recall that $I$ holds controlling cash flow rights $\alpha_{A}>0$ in firm $A$, and non-controlling or controlling cash flow rights $\tilde{\alpha}_{B}=\alpha_{B}+\alpha_{A} \gamma \geq 0$ in firm $B$. Let $\omega \in[0, \infty)$ denote investor I's share of cash flow rights in firm $B$ relative to those held in firm $A$, i.e. define $\omega \equiv \tilde{\alpha}_{B} / \alpha_{A} \in\left[0,1 / \alpha_{A}\right]$.

\subsection{Firm $B$ not controlled by $I$}

If $I$ owns $\alpha_{A}$ controlling shares in firm $A$ and $\tilde{\alpha}_{B}$ non-controlling shares in firm $B$ she solves

$$
\max _{p_{A}} \pi_{A}\left(p_{A}, p_{B}\right)+\omega \cdot \pi_{B}\left(p_{A}, p_{B}\right)
$$

Firm $B$ 's price $p_{B}$ is set such that it maximizes $B$ 's profits, hence

$$
\max _{p_{B}} \pi_{B}\left(p_{A}, p_{B}\right)
$$

The respective best responses are given by

$$
B R_{A}\left(p_{B}\right)=\left\{p_{A}\left(p_{B}\right) \mid \frac{\partial \pi_{A}\left(p_{A}, p_{B}\right)}{\partial p_{A}}+\omega \cdot \frac{\partial \pi_{B}\left(p_{A}, p_{B}\right)}{\partial p_{A}}=0\right\}
$$


and

$$
B R_{B}\left(p_{A}\right)=\left\{p_{B}\left(p_{A}\right) \mid \frac{\partial \pi_{B}\left(p_{A}, p_{B}\right)}{\partial p_{B}}=0\right\} .
$$

Assumption (iii) guarantees that the second order conditions

$$
\frac{\partial^{2} \pi_{A}\left(p_{A}, p_{B}\right)}{\partial p_{A}^{2}}+\omega \cdot \frac{\partial^{2} \pi_{B}\left(p_{A}, p_{B}\right)}{\partial p_{A}^{2}}<0
$$

and

$$
\frac{\partial^{2} \pi_{B}\left(p_{A}, p_{B}\right)}{\partial p_{B}^{2}}<0
$$

are satisfied for all $\omega \in\left[0,1 / \alpha_{A}\right]$. Together with the first part of Assumption (iv) we have that the best responses are both positively sloped, as both

$$
\frac{\partial B R_{A}\left(p_{B}\right)}{\partial p_{B}}=-\frac{\frac{\partial^{2} \pi_{A}\left(p_{A}, p_{B}\right)}{\partial p_{A} \partial p_{B}}+\omega \cdot \frac{\partial^{2} \pi_{B}\left(p_{A}, p_{B}\right)}{\partial p_{A} \partial p_{B}}}{\frac{\partial^{2} \pi_{A}\left(p_{A}, p_{B}\right)}{\partial p_{A}^{2}}+\omega \cdot \frac{\partial^{2} \pi_{B}\left(p_{A}, p_{B}\right)}{\partial p_{A}^{2}}}
$$

and

$$
\frac{\partial B R_{B}\left(p_{A}\right)}{\partial p_{A}}=-\frac{\frac{\partial^{2} \pi_{B}\left(p_{A}, p_{B}\right)}{\partial p_{A} \partial p_{B}}}{\frac{\partial^{2} \pi_{B}\left(p_{A}, p_{B}\right)}{\partial p_{B}^{2}}}
$$

are strictly positive. Denote by $\left(p_{A}^{O}(\omega), p_{B}^{O}(\omega)\right)$ a Nash equilibrium price vector. The equilibrium is stable if

$$
\frac{\partial\left(B R_{A}\right)^{-1}\left(p_{A}^{O}(\omega)\right)}{\partial p_{A}}>\frac{\partial B R_{B}\left(p_{A}^{O}(\omega)\right)}{\partial p_{A}} .
$$

In our analysis, we consider only the case of a stable unique equilibrium.

In the following Proposition we characterize Nash equilibrium prices and profits as a func- 
tion of $\omega$, the relative share of cash flow rights held by investor $I$ in firm $B$ over firm $A$.

Proposition 1 (Equilibrium Prices and Profits under Separate Control): Let I control firm A only, so that the two firms compete with each other à la Bertrand. Then,

(i) $p_{A}^{O}(\omega)>p_{B}^{O}(\omega)$ for all $\omega>0$,

(ii) $\pi_{A}\left(p_{A}^{O}(\omega), p_{B}^{O}(\omega)\right)<\pi_{B}\left(p_{A}^{O}(\omega), p_{B}^{O}(\omega)\right)$ for all $\omega>0$,

(iii) $p_{A}^{O}(\omega)$ and $p_{B}^{O}(\omega)$ strictly increase for all $\omega>0$, with $\partial p_{A}^{O}(\omega) / \partial \omega>\partial p_{B}^{O}(\omega) / \partial \omega$, and

(iv) there is an $\omega^{O}$ such that $\pi_{A}\left(p_{A}^{O}(\omega), p_{B}^{O}(\omega)\right)$ increases for small $\omega \leq \omega^{O}$, and strictly decreases thereafter. $\pi_{B}\left(p_{A}^{O}(\omega), p_{B}^{O}(\omega)\right)$ strictly increases for all $\omega>0$.

The main effect of $I$ 's acquisition of cash flow rights in $B$ under separate control is that $I$ internalizes the effect of an increase in $p_{A}$-implying an increase in $p_{B}$-on the profits $\pi_{B}\left(p_{A}, p_{B}\right)$. This yields to an initial increase in $\pi_{A}\left(p_{A}, p_{B}\right)$, and an increase in relative profits $\pi_{B}\left(p_{A}, p_{B}\right) / \pi_{A}\left(p_{A}, p_{B}\right)$ throughout. As a direct corollary it emerges that, provided that demand is downward sloping, consumer welfare as measured by consumer surplus decreases with an increase in $\omega$, as long as no controlling stake is associated with that increase. We cannot say much about changes in total welfare, as this would necessitate specifying demand in order to compare negative changes in consumer to positive changes in producer surplus. ${ }^{5}$

\subsection{Firm $B$ controlled by $I$}

We now consider the case in which $I$ holds a controlling stake in both firms $A$ and $B$. Then, $I$ solves

$$
\max _{p_{A}, p_{B}} \pi_{A}\left(p_{A}, p_{B}\right)+\omega \cdot \pi_{B}\left(p_{A}, p_{B}\right) .
$$

\footnotetext{
${ }^{5}$ In a Hotelling example involving constant marginal costs we find a decrease also in total welfare when $\omega$ increases.
} 
The first order conditions are given by

$$
\frac{\partial \pi_{A}\left(p_{A}, p_{B}\right)}{\partial p_{A}}+\omega \cdot \frac{\partial \pi_{B}\left(p_{A}, p_{B}\right)}{\partial p_{A}}=0
$$

and

$$
\frac{\partial \pi_{A}\left(p_{A}, p_{B}\right)}{\partial p_{B}}+\omega \cdot \frac{\partial \pi_{B}\left(p_{A}, p_{B}\right)}{\partial p_{B}}=0
$$

We assume the second order conditions to be satisfied, a requirement which is slightly stronger than Assumptions (ii) to (iv). Denote the optimal prices by $\left(p_{A}^{M}(\omega), p_{B}^{M}(\omega)\right)$.

Proposition 2 (Optimal Prices and Profits under Joint Control): Let I control both firms and let $\omega>0$. Then,

(i) $p_{A}^{M}(\omega) \lesseqgtr p_{B}^{M}(\omega)$ if $\omega \lesseqgtr 1$,

(ii) $\pi_{A}\left(p_{A}^{M}(\omega), p_{B}^{M}(\omega)\right) \gtreqless \pi_{B}\left(p_{A}^{M}(\omega), p_{B}^{M}(\omega)\right)$ for all $\omega \lesseqgtr 1$,

(iii) $p_{A}^{M}(\omega)$ strictly increases and $p_{B}^{M}(\omega)$ strictly decreases,

(iv) $\pi_{A}\left(p_{A}^{M}(\omega), p_{B}^{M}(\omega)\right)$ strictly decreases and $\pi_{B}\left(p_{A}^{M}(\omega), p_{B}^{M}(\omega)\right)$ strictly increases.

The intuition behind these results is that in the firm that carries the higher weight in investor I's portfolio of shares, the relative price is lower, so as to attract relatively more customers, and the resulting profit is higher. Observe in particular that if the controlling stakes $\alpha_{A}, \alpha_{B}$ and $\gamma$ are such that $\omega=1$, the monopoly solution obtains, no matter how small the stakes actually are. We will see later that $I$ will make use of the fact that the desired product market allocation result can be obtained without fully acquiring both firms.

Finally, it follows from a comparison of the necessary conditions and from the strategic complementarity of prices that $p_{B}^{O}(\omega)<p_{A}^{O}(\omega)<p_{A}^{M}(\omega)<p_{B}^{M}(\omega)$ when $\omega<1$ and $p_{B}^{O}(\omega)<$ 
$p_{A}^{O}(\omega)<p_{B}^{M}(\omega)<p_{A}^{M}(\omega)$ when $\omega>1$. This allows us to rank the outcomes from the acquisition game from a consumer surplus point of view. It is not possible, though, to completely rank the firms' profits under the general assumptions made here.

\section{Acquisition Stage}

Before we formally analyze the first stage of the game involving investor I's acquisition decisions, let us obtain an intuition about the forces bearing on them. These are the gains per acquired share; the leverage from indirect acquisition via the controlled firm $A$, vs. direct acquisition by $I$; and the change in product prices and thus profits resulting from the acquisition decisions.

As to the gains per acquired share: Since $I$ is by assumption the only active investor, she can make a take-it-or-leave-it offer at the minimal share price acceptable to the respective incumbent seller. That price is determined by the seller's outside option. The seller is called pivotal if I can take profit increasing allocation decisions only when the seller has accepted to sell. Then the seller's outside option is given by the value of his shares once investor $I$ pursues her most profitable activity without purchasing these shares.

By contrast, the incumbent shareholder is called non-pivotal if selling his shares has no bearing on the allocation decisions taken by $I$. This shareholder's outside option consists of the share price obtained when investor $I$ has chosen her profit maximizing allocation.

In view of our assumptions on the structure of firm $B$ 's initial ownership, we observe that the single owner $I_{B}$ of firm $B$ is obviously pivotal, because by selling shares he transfers cash flow rights and possibly control to investor $I$. By contrast, if firm $B$ is held by many equally sized small shareholders, then the probability of any single shareholder becoming pivotal in the sense of transferring cash flow and possibly control rights is very small. For simplicity, we assume this probability to be zero. ${ }^{6}$

\footnotetext{
${ }^{6}$ In that, we follow Grossman and Hart (1980). This is clearly at variance with Bagnoli and Lipman (1988) or
} 
The effect of leveraging acquisitions via the controlled firm $A$ is quite simple: Since by assumption investor $I$ initially owns controlling shares $\alpha_{A}^{0}<1$ in firm $A$, acquiring $\gamma$ shares indirectly via firm $A$ costs her $\alpha_{A}^{0} \gamma<\gamma$ times the acquisition price, whence acquiring those shares directly costs her $\gamma$ times that price. Thus, an indirect acquisition reduces the transactions costs born by the investor. Of course, all of this comes with a proportional reduction in the profits obtained from the acquired shares.

Finally, the changes in product prices and profits resulting from I's acquisitions are determined in stage 2. The main drivers are parts (iv) of each of Propositions 1 and 2, showing how profits move as a function of the control exercised by investor $I$, and of $\omega$, the share of cash flow rights $I$ ultimately holds in the two firms.

As to the specifics of obtaining an equilibrium ownership structure when initially shares are held by small shareholders: If, for instance, in firm $B$ the initial ownership is dispersed, then investor $I$ quotes an offer price $P_{B}^{k}(\omega), k=O, M$, per share, that attracts a fraction $\alpha_{B}+\gamma$ of all shares outstanding. This price is solely determined by the profits obtained from firm $B$ 's product market activity, which depends on the relative cash flow rights $I$ holds in $B$ and on whether she obtains control. Following Burkart, Gromb, and Panunzi (1998), we use the concept of a rational expectations equilibrium in which all shareholders behave symmetrically, each shareholder tendering her shares with probability $\alpha_{B}+\gamma$, and retaining them with probability $1-\alpha_{B}-\gamma$.

In equilibrium, every single small shareholder is indifferent between tendering or not, and believes that both the acquisition of cash flow and/or control rights in firm $B$ by $I$ does not depend on her decision. Therefore, and by an analogous argument on firm A's dispersed shareholders, the offer price for $\alpha_{i}$ shares in firm $i$ is equal to $\alpha_{i} \cdot \pi_{i}\left(p_{A}^{k}(\omega), p_{B}^{k}(\omega)\right), k=O, M$, whichas shown in Section 3-depends on I's stakes in $A$ and $B$, and on whether she obtains control in Holmstrom and Nalebuff (1992). Yet it simplifies our argument essentially without distortion. 
$B$. Formally, letting $\pi_{i}^{k}(\omega) \equiv \pi_{i}\left(p_{A}^{k}(\omega), p_{B}^{k}(\omega)\right), i=A, B, k=O, M$,

$$
\begin{aligned}
& P_{A}^{k}(\omega)=\pi_{A}^{k}(\omega)+\gamma \cdot\left[\pi_{B}^{k}(\omega)-P_{B}^{k}(\omega)\right] \\
& P_{B}^{k}(\omega)=\pi_{B}^{k}(\omega) .
\end{aligned}
$$

I faces the free rider problem discussed by Grossman and Hart (1980) when acquiring shares from dispersed owners: Because shareholders rationally expect the consequences of that acquisition on firm profits, the acquisition price fully incorporates the allocation gains to firm $B$. Hence, I can never gain directly from acquiring (additional) cash flow rights when (remaining) ownership is dispersed, as the acquisition price is always equal to the profits she will earn from the acquired shares. Yet by investing in firm $B, I$ may benefit from an increased value of her initial stake in firm $A$ due to changes in the product market allocation. This argument extends into the acquisition of additional shares in firm $A$. In all, if the (remaining) ownership is dispersed, our acquiring investor $I$ has de facto no bargaining power.

By contrast, if the target shares of one of the firms $i, i=A, B$, are held by one block holder, then all bargaining power rests with the acquiring investor $I$, so that she can absorb all the surplus generated from that acquisition. Accordingly, the acquisition price per share is determined by equalizing the seller's payoff obtained when selling some of his shares to $I$, and enjoying the profits from his remaining shares, to his outside option, which is the payoff generated when selling no shares at all.

In the ensuing analysis we concentrate on investor I's overall payoff from acquiring cash flow rights $\left(\alpha_{A}-\alpha_{A}^{0}\right)$ in firm $A$ and $\alpha_{B}$ in firm $B$, respectively. It is given by

$$
\Pi^{k}(\omega)=\alpha_{A}\left[\pi_{A}^{k}(\omega)+\gamma\left(\pi_{B}^{k}(\omega)-P_{B}^{k}(\omega)\right)\right]-\left(\alpha_{A}-\alpha_{A}^{0}\right) P_{A}^{k}(\omega)+\alpha_{B}\left[\pi_{B}^{k}(\omega)-P_{B}^{k}(\omega)\right],
$$

where $k=O, M, \omega=\left(\alpha_{B}+\alpha_{A} \gamma\right) / \alpha_{A}, \alpha_{A} \in\left[\alpha_{A}^{0}, 1\right], \alpha_{B} \in[0,1], \gamma \in[0,1]$, and $\alpha_{B}+\gamma \leq 1$.

The first term reflects her share $\alpha_{A}$ of the payoffs from her interest in firm $A$, including the 
one that comes from the stake acquired by firm $A$ in firm $B$; the second term the acquisition costs of an additional stake $\left(\alpha_{A}-\alpha_{A}^{0}\right)$; and the third term the payoffs net of acquisition costs from a stake $\alpha_{B}$ in firm $B$ directly acquired by investor $I$.

To make our arguments transparent, we sometimes separately consider the determination of the relative weight $\omega$ and its composition; that is, the trade off between the direct acquisition of $\alpha_{B}$ shares, vs. the indirect acquisition of $\gamma$ shares via firm $A$; and the increase in I's stakes in firm $A$ over and above $\alpha_{A}^{0}$, vs. the acquisition of a stake in firm $B$; finally the acquisition of cash flow rights only, vs. that of control rights in $B$. Notice that acquisition prices depend only on $\omega$ and whether $I$ acquires control in $B$, but not on $\alpha_{A}, \alpha_{B}$ and $\gamma$ directly. The reason is that the allocation effects reflect only the relative share of I's holdings in the two firms.

\subsection{Case 1: Both, Remaining Shares in $A$ and Shares in $B$ Dispersed}

In this first case, all shares $I$ can acquire are held by non-pivotal shareholders who claim the ex post profits generated by the investor. Therefore, I's payoff reduces to the payoff generated from the shares he holds initially. Formally, using (11) specifying the acquisition price when the (remaining) ownership is dispersed in both firms, investor I's overall acquisition payoff (12) reduces to

$$
\Pi^{k}(\omega)=\alpha_{A}^{0} \cdot \pi_{A}^{k}(\omega), k=O, M
$$

which she seeks to maximize with respect to $k$ and $\omega$ using the mode of acquisition with the lowest acquisition costs. The solution to this maximization problem is condensed in

Proposition 3: Let the remaining initial ownership in firm $A$ and the ownership of firm $B$ be both dispersed. Let $\omega^{M}$ satisfy $\pi_{A}^{O}\left(\omega^{O}\right)=\pi_{A}^{M}\left(\omega^{M}\right)$. Then

(i) I acquires indirectly a minimal stake in firm B via firm A. 


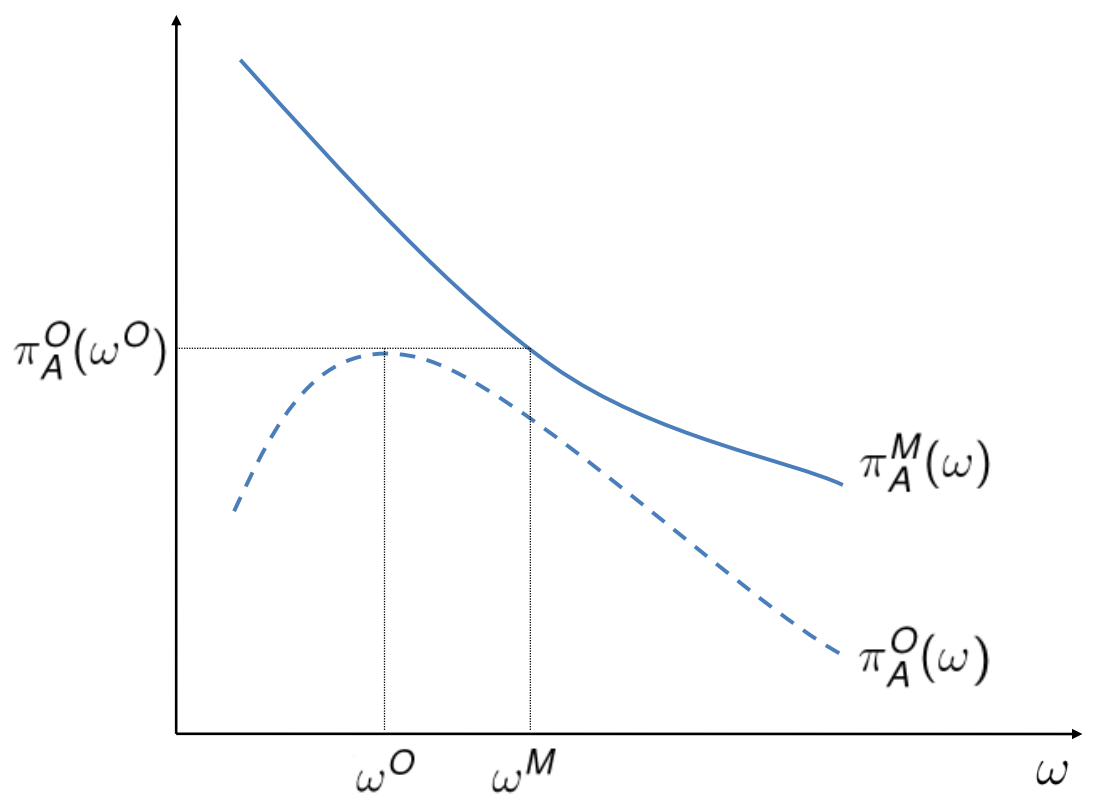

Figure 2: Dependence of profits on $\omega$.

(ii) If $\hat{\alpha}_{B} \leq \omega^{M}$, that stake is controlling, so that $\gamma^{*}=\hat{\alpha}_{B}, \alpha_{B}^{*}=0$, and $\omega^{*}=\hat{\alpha}_{B}$.

Furthermore, $p_{A}^{M}\left(\hat{\alpha}_{B}\right)<p_{B}^{M}\left(\hat{\alpha}_{B}\right)$ and $\pi_{A}^{M}\left(\hat{\alpha}_{B}\right)>\pi_{B}^{M}\left(\hat{\alpha}_{B}\right)$.

(iii) If $\hat{\alpha}_{B}>\omega^{M}$, that stake is non-controlling, so that $\gamma^{*}=\omega^{O}, \alpha_{B}^{*}=0$, and $\omega^{*}=\omega^{O}$.

Furthermore, $p_{A}^{O}\left(\omega^{O}\right)>p_{B}^{O}\left(\omega^{O}\right)$ and $\pi_{A}^{O}\left(\omega^{O}\right)<\pi_{B}^{O}\left(\omega^{O}\right)$.

For the intuition consult Figure 2. The shapes of the payoffs are determined in parts (iv) of Propositions 1 and 2, respectively. $\omega^{M}$ is defined by equating the payoffs $\pi_{A}^{O}\left(\omega^{O}\right)$ and $\pi_{A}^{M}(\omega)$. Since $\pi_{A}^{M}(\omega)$ is strictly decreasing, $\pi_{A}^{O}\left(\omega^{O}\right)<\pi_{A}^{M}\left(\hat{\alpha}_{B}\right)$ if $\hat{\alpha}_{B} \leq \omega^{M}$, i.e. obtaining a minimal controlling share in firm $B$ is more profitable to investor $I$. In this situation the minimal block $\hat{\alpha}_{B}$ required to obtain control in firm $B$ is small relative to the share $I$ initially holds in $A$. By contrast, if $\hat{\alpha}_{B}>\omega^{M}$, we have that $\pi_{A}^{O}\left(\omega^{O}\right)>\pi_{A}^{M}\left(\hat{\alpha}_{B}\right)$, and the investor prefers to obtain a noncontrolling share in $B$. The reason is that acquiring small non-controlling cash flow rights in $B$ increases duopoly equilibrium prices and thus not only the payoffs to firm $B$, but also to firm $A$. 
Observe finally that the product market outcome in the two subcases dramatically differs: when acquiring a controlling stake in firm $B, I$ decides to use that control to shift profits into firm $A$, while she is not able to do that when just acquiring cash flow rights in $B$.

\subsection{Case 2: Remaining Shares in $A$ Concentrated and all Shares in $B$ Dis- persed}

Here the remaining shares in firm $A$ are held by investor $I_{A}$. At any equilibrium acquisition price for $\alpha_{B}-\alpha_{A}^{0}$ shares, $I_{A}$ must be at least indifferent between selling and keeping them. Hence the acquisition price for $\alpha_{A}-\alpha_{A}^{0}$ additional shares in $A, P_{A}^{k}(\omega)$, conditional on investor $I$ 's acquisition of non-controlling $(k=O)$ vs. controlling shares $(k=M)$ in firm $B$ must satisfy

$$
\left(\alpha_{A}-\alpha_{A}^{0}\right) \cdot P_{A}^{k}\left(\omega^{k}\right)+\left(1-\alpha_{A}\right) \cdot\left[\pi_{A}^{k}\left(\omega^{k}\right)+\gamma\left(\pi_{B}^{k}\left(\omega^{k}\right)-P_{B}^{k}\left(\omega^{k}\right)\right)\right]=\left(1-\alpha_{A}^{0}\right) \cdot \pi_{A}^{k}\left(\omega^{k}\right), k=O, M
$$

The left hand side of (14) is the payoff to $I_{A}$ in case he sells the fraction $\left(\alpha_{A}-\alpha_{A}^{0}\right)$ of firm $A$ 's shares to $I$, and the right hand side is his payoff if he does not sell. That payoff, however, eventually reflects $I$ 's engagement in firm $B$, on which $I_{A}$ is able to free ride.

Since firm $B$ 's initial ownership is dispersed as in case 1 , we have $P_{B}(\omega)=\pi_{B}\left(\omega^{k}\right)$, so that

$$
P_{A}^{k}\left(\omega^{k}\right)=\frac{\left(1-\alpha_{A}^{0}\right) \cdot \pi_{A}^{k}\left(\omega^{k}\right)-\left(1-\alpha_{A}\right) \cdot \pi_{A}^{k}\left(\omega^{k}\right)}{\alpha_{A}-\alpha_{A}^{0}}=\pi_{A}^{k}\left(\omega^{k}\right) .
$$

Since the purchase price of shares exactly reflects the payoffs generated from an engagement in firm $B, I$ 's choice as to that remains unchanged with the structure of the remaining ownership in firm $A$. Hence,

Proposition 4: Let the remaining initial ownership in firm A be concentrated and the ownership of firm B dispersed. Then the results of Proposition 3 carry over. 
The reason for this surprising result is that as $I$ already controls firm $A$, the block owner $I_{A}$ of its residual stake is non-pivotal. Thus the price at which $I_{A}$ is willing to sell shares reflects all of I's other acquisition decisions, resulting in a profitable improvement of the allocation. In other words, $I_{A}$ free rides on $I$ 's activity. This implies that also in this case, $I$ does not benefit from the acquisition per se, so that her objective, and thus the results remain the same as in case 1.

Observe finally that Propositions 3 and 4 together imply that any structure of the remaining ownership in firm $A$ generates the outcome of the acquisition game characterized in Proposition 3.

\subsection{Case 3: Remaining Shares in $A$ Dispersed and Ownership of $B$ Con- centrated}

In contrast to case 1 , here all stakes in firm $B$ are initially held by only one investor $I_{B}$, who by assumption is not invested in $A$. Again, the equilibrium acquisition price for $\alpha_{B}+\gamma$ shares in firm $B$ is determined so that $I_{B}$ is indifferent between selling and keeping them. It thus satisfies

$$
\left(\alpha_{B}+\gamma\right) \cdot P_{B}^{k}(\omega)+\left(1-\alpha_{B}-\gamma\right) \cdot \pi_{B}^{k}(\omega)=\pi_{B}^{O}(0), k=O, M
$$

when $\omega=\left(\alpha_{B}+\alpha_{A} \gamma\right) / \alpha_{A}>0$. Notice that $I_{B}$ 's outside option on the right hand side is to obtain $\pi_{B}^{O}(0)$, firm $B$ 's (and therefore, $I_{B}$ 's) profit without any interest of $I$ in $B$. Solving for $P_{B}^{k}(\omega)$ and comparing to (11) reflecting the acquisition price in which ownership in firm $B$ is dispersed, we see that the benefits accruing to investor $I$ from acquiring a stake in $B$ are shared with $I_{B}$ only if $\alpha_{B}+\gamma<1$. The reason is that investor $I_{B}$ is pivotal, by initially controlling firm $B$.

As in case 1, the acquisition price for shares in firm $A$ is equal to the ex post value of $A$. 
Substituting, we obtain

$$
P_{A}^{k}(\omega)=\pi_{A}^{k}(\omega)+\gamma\left\{\pi_{B}^{k}(\omega)-\frac{1}{\alpha_{B}+\gamma} \cdot\left[\pi_{B}^{O}(0)-\left(1-\alpha_{B}-\gamma\right) \cdot \pi_{B}^{k}(\omega)\right]\right\}, k=O, M
$$

Investor I's overall payoff is now

$$
\begin{aligned}
\Pi^{k}(\omega)= & \alpha_{A} \cdot\left(\pi_{A}^{k}(\omega)+\gamma \cdot\left\{\pi_{B}^{k}(\omega)-\frac{1}{\alpha_{B}+\gamma} \cdot\left[\pi_{B}^{O}(0)-\left(1-\alpha_{B}-\gamma\right) \cdot \pi_{B}^{k}(\omega)\right]\right\}\right) \\
& +\alpha_{B} \cdot\left\{\pi_{B}^{k}(\omega)-\frac{1}{\alpha_{B}+\gamma} \cdot\left[\pi_{B}^{O}(0)-\left(1-\alpha_{B}-\gamma\right) \cdot \pi_{B}^{k}(\omega)\right]\right\} \\
& -\left(\alpha_{A}-\alpha_{A}^{0}\right) \cdot P_{A}^{k}(\omega), k=O, M .
\end{aligned}
$$

This simplifies to

$$
\Pi^{k}(\omega)=\alpha_{A}^{0} \cdot \pi_{A}^{k}(\omega)+\frac{\alpha_{B}+\alpha_{A}^{0} \gamma}{\alpha_{B}+\gamma} \cdot\left[\pi_{B}^{k}(\omega)-\pi_{B}^{O}(0)\right], k=O, M
$$

The first term is the value of $I$ 's initial stake in $A$ and the second term is $I$ 's net benefit from directly and/or indirectly acquiring $\alpha_{B}+\gamma$ shares in $B$. The bracketed term refers to the change in firm $B$ 's profit from investor $I$ 's intervention. It is weighed by the profit share $I$ can absorb from acquisition, divided by the share acquired directly or indirectly.

In the following proposition we establish that $\Pi_{1}^{k}(\omega)$ is maximized for $k=M, \alpha_{B}=1, \gamma=0$, and $\alpha_{A}=\alpha_{A}^{0}$. This reflects I's interest in fully internalizing the positive acquisition gains in firm $B$ via $\alpha_{B}=1$, whilst otherwise these acquisition gains would have to be shared with the owners of the remaining shares in firm $A$.

Proposition 5: Let the remaining initial ownership in firm A be dispersed and the ownership of firm B concentrated. Then I acquires the maximal controlling stake in firm B and no additional stake in firm A, such that $\alpha_{B}^{*}=1, \gamma^{*}=0$, and $\omega^{*}=1 / \alpha_{A}^{0}$.

Furthermore, $p_{A}^{M}\left(1 / \alpha_{A}^{0}\right)>p_{B}^{M}\left(1 / \alpha_{A}^{0}\right)$, and $\pi_{A}^{M}\left(1 / \alpha_{A}^{0}\right)<\pi_{B}^{M}\left(1 / \alpha_{A}^{0}\right)$. 
Despite a somewhat involved proof, the intuition for this result is quite straightforward. As $I_{B}$ is pivotal, investor $I$ acquires firm $B$ completely because she can realize acquisition gains. She does not, however, symmetrically increase her share in firm $A$ towards full monopoly in spite of the fact that this would maximize industry profits, because she could do so only at zero acquisition gains in firm $A$. In fact, under symmetric monopoly, profits would be reshuffled into firm $A$, to the advantage of the non-pivotal shareholders. In consequence, the asymmetry in the equilibrium ownership structure is reflected in industry prices and profits: Firm $B$ 's prices are lower than firm A's prices, which results in a larger output market share and higher profits.

Note finally that by these arguments, the Proposition generalizes easily to include more complex forms of ownership in firm $B$. In particular, let firm $B$ be controlled by $I_{B}$ with a block $\delta$, and let the remaining share volume $(1-\delta)$ be held by dispersed shareholders. Then $I$ will acquire the block $\delta$ from $I_{B}$, and thus control both firms with the blocks $\alpha_{A}^{0}$ and $\delta$, respectively.

\subsection{Case 4: Remaining Shares in $A$, and Shares in $B$ Concentrated}

We finally study the case in which the shares in $B$ are initially held by $I_{B}$ as in the preceding case 3 , but at the same time the remaining shares in $A$ are held by investor $I_{A}$, as in case 2 .

Once again, the acquisition price $P_{A}^{k}(\omega)$ for additional shares in $A$ is influenced by investor $I_{A}$ 's outside option if he does not sell shares to $I$. From case 3 , we know that if acquiring a stake in firm $B, I$ does so directly, because the return per acquired share is positive when obtained from a pivotal shareholder.

The share price $P_{A}^{k}(\omega)$ making $I_{A}$ indifferent between selling and not selling satisfies ${ }^{7}$

(18) $\left(\alpha_{A}-\alpha_{A}^{0}\right) \cdot P_{A}^{k}(\omega)+\left(1-\alpha_{A}\right) \cdot\left[\pi_{A}^{k}(\omega)+\gamma\left(\pi_{B}^{k}(\omega)-P_{B}^{k}(\omega)\right)\right]=\left(1-\alpha_{A}^{0}\right) \cdot \pi_{A}^{M}\left(1 / \alpha_{A}^{0}\right), k=O, M$.

\footnotetext{
${ }^{7}$ Without acquiring a stake in $A$, the option of fully acquiring $B$ is more valuable to investor $I$ than not acquiring $B$, as $\alpha_{A}^{0} \pi_{A}^{O}\left(p_{A}^{O}, p_{B}^{O}\right)<\alpha_{A}^{0} \pi_{A}^{M}\left(p_{A}^{M}, p_{B}^{M}\right)+\pi_{B}^{M}\left(p_{A}^{M}, p_{B}^{M}\right)-\pi_{B}^{O}\left(p_{A}^{O}, p_{B}^{O}\right)$, by the principle of optimization.
} 
In turn, the share price making $I_{B}$ indifferent between selling and not selling is determined by

$$
\left(\alpha_{B}+\gamma\right) \cdot P_{B}^{k}(\omega)+\left(1-\alpha_{B}-\gamma\right) \cdot \pi_{B}^{k}(\omega)=\pi_{B}^{O}(0)
$$

Substituting (18) and (19) into (12) and simplifying, we obtain, after some algebra,

$$
\Pi^{k}(\omega)=\pi_{A}^{k}(\omega)+\pi_{B}^{k}(\omega)-\left(1-\alpha_{A}^{0}\right) \cdot \pi_{A}^{M}\left(1 / \alpha_{A}^{0}\right)-\pi_{B}^{O}(0), k=O, M,
$$

Thus, I's payoff is given by the sum of profits of both firms less the outside options of $I_{A}$ and $I_{B}$, respectively. Observe that the latter are independent of $I$ 's choice of $\omega$. Hence investor $I$ 's payoff is maximized for any $\omega=1$. In view of minimizing her transactions cost, this is achieved by indirectly acquiring the threshold block volume $\hat{\alpha}_{B}$. If $\alpha_{A}^{0}<\hat{\alpha}_{B}$, then $I$ acquires in addition the difference $\hat{\alpha}_{B}-\alpha_{A}^{0}$, towards maximizing the monopoly outcome, which by Assumption (v) is obtained under symmetry. By the principle of optimization, this dominates the oligopoly outcome. We summarize in

Proposition 6: Let the remaining initial ownership in firm $A$ and the ownership of firm $B$ be both concentrated. Then,

(i) if $\hat{\alpha}_{B} \leq \alpha_{A}^{0}$, I acquires a controlling stake in firm B, and no additional stake in firm A. $I$ is indifferent between indirectly fully acquiring firm $B$ so that $\gamma^{*}=1$ and $\alpha_{B}^{*}=0$, and directly acquiring a stake $\alpha_{B}^{*}=\alpha_{A}^{0}$ with $\gamma^{*}=0$;

(ii) if $\hat{\alpha}_{B}>\alpha_{A}^{0}$, then I acquires additional $\left(\hat{\alpha}_{B}-\alpha_{A}^{0}\right)$ shares in firm A, so that $\omega^{*}=1$ in both cases.

Hence, contrary to what one might have expected, complete ownership of both firms is not the outcome of the acquisition game, even if the ownership is concentrated and $I$ can extract rents from the acquisition per se. Within the framework considered here the reason is that $I$ 
has full bargaining power. She will buy less shares in $B$ only if adequately compensated by the seller of shares in B. ${ }^{8,9}$

\section{Extensions}

We consider our model as a baseline that invites many extensions. Of those, we wish to consider here the two we feel most inviting: first, that with the acquisition of control rights in firm $B$ our active investor $I$ may force that firm to buy shares in firm $A$; and second, that in contrast to Assumption (v), not the symmetric monopoly maximizes industry profits, but monopoly exercised by just one firm. This is obviously the case when the two products considered are close substitutes and the fixed costs of operating a firm are large relative to the degree of substitutability.

\subsection{Cross ownership arrangements}

Consider the first extension, and ask whether our active investor $I$ will ever find it profitable that firm $B$, if controlled by her, buys additional shares in $A$. We have so far excluded this possibility. We show that $I$ will never find this profitable, so our analysis continues to hold.

Recall that in cases 1 and 2, if $I$ found it profitable to control $B$, she acquired shares in firm $B$ indirectly through firm $A$. The reason was that in these cases $B$ is initially owned by dispersed shareholders claiming ex post profits. Hence $I$ has no interest in directly acquiring shares, but rather minimizes the transactions costs of acquiring the shares in $B$ needed to increase the profits in the stake already held. Conversely, in cases 3 and 4 in which $B$ is initially owned by a large investor, she directly acquires all stakes in $B$, in order to fully pocket the acquisition gains.

\footnotetext{
${ }^{8}$ Observe that the prices $P_{i}^{k}(\omega), i=A, B, k=O, M$ at which $I$ acquires shares from block holders could be negative. Negative prices could be interpreted as side payments to $I$, due to the benefits accruing to $I$ by changing the product market allocation and increasing industry profits. Alternatively, one could restrict all prices to be at least as large as the share prices reflecting the ex ante profits, without essentially changing the results. In particular, the result will be upheld that while inducing a symmetric monopoly, $I$ does not do so by acquiring all of the two firms' shares.

${ }^{9}$ Only in this case where the block holdings in both firms influence $I$ 's acquisition decisions in a delicate way does the proposition not as easily generalize into more general ownership structures. The discussion of this must be left for another paper.
} 
Denote the investment $A$ makes in $B$ by $\gamma_{B}$ and the investment $B$ makes in $A$ by $\gamma_{A}$, analogously to the respective direct investments by $I$, which are denoted by $\alpha_{A}$ and $\alpha_{B}$. Then, the effective cash flow rights $I$ holds in $B$ are $\alpha_{B}+\alpha_{A} \gamma_{B}+\alpha_{B} \gamma_{A} \gamma_{B}+\alpha_{A} \gamma_{B} \gamma_{A} \gamma_{B}+\alpha_{B} \gamma_{A} \gamma_{B} \gamma_{A} \gamma_{B}+$ $\alpha_{A} \gamma_{B} \gamma_{A} \gamma_{B} \gamma_{A} \gamma_{B}+\cdots=\left(\alpha_{B}+\alpha_{A} \gamma_{B}\right)\left(1+\gamma_{A} \gamma_{B}+\left(\gamma_{A} \gamma_{B}\right)^{2}+\left(\gamma_{A} \gamma_{B}\right)^{3}+\ldots\right.$ The effective cash flow rights $I$ holds in $A$ are $\alpha_{A}+\alpha_{B} \gamma_{A}+\alpha_{A} \gamma_{B} \gamma_{A}+\alpha_{B} \gamma_{A} \gamma_{B} \gamma_{A}+\alpha_{A} \gamma_{B} \gamma_{A} \gamma_{B} \gamma_{A}+\alpha_{B} \gamma_{A} \gamma_{B} \gamma_{A} \gamma_{B} \gamma_{A}+\cdots=$ $\left(\alpha_{A}+\alpha_{B} \gamma_{A}\right)\left(1+\gamma_{B} \gamma_{A}+\left(\gamma_{B} \gamma_{A}\right)^{2}+\left(\gamma_{B} \gamma_{A}\right)^{3}+\ldots\right.$ Therefore, the effective cash flow rights $I$ holds in $B$ relative to $A$ are now

$$
\omega=\frac{\alpha_{B}+\alpha_{A} \gamma_{B}}{\alpha_{A}+\alpha_{B} \gamma_{A}}
$$

In cases 1 and $2 I$ continues to keep transactions costs as small as possible, so she will still make firm $A$ buy a minimal controlling stake in $B$, with $\gamma_{B}=\hat{\alpha}_{B}$ and $\alpha_{B}=0$. In case 3 she will still want to buy a maximal controlling stake herself, and in case 4 she will aim at setting $\omega=1$ either by choosing $\gamma_{B}=1$ along with $\alpha_{A}=\alpha_{A}^{0}, \alpha_{B}=0$ and $\gamma_{A}=0$; or $\gamma_{B}=0$ along with $\alpha_{A}=\alpha_{A}^{0}, \alpha_{B}=\alpha_{A}^{0}$ and $\gamma_{A}=0$.

\subsection{Firm shutdowns}

Let us now turn to conditions under which an industry involving a one product monopoly is more profitable than one involving a two product monopoly. Recall that Assumption (v) stated that industry profits are maximal at the unweighed sum of the two firms' profits at monopoly prices. We now replace Assumption (v) by Assumption

(v') $\pi_{A}\left(p_{A}, p_{B}\right)+\pi_{B}\left(p_{A}, p_{B}\right)$ is maximal at $p_{i}=p_{i}^{M}, p_{j}=\infty, i, j=A, B, i \neq j$.

This situation obviously obtains if $A$ and $B$ offer close substitutes, and there is a fixed cost to maintain each one of the two production processes. In order to give precision to this, let $\sigma \in[0,1]$ denote the degree of substitutability between the two products, with $\sigma=0$ referring to the case where the two products are unrelated, and $\sigma=1$ to the case where the two products are perfect substitutes. Augment the two profit functions by $\sigma$. Let $F$ denote the fixed cost 
necessary to implement the production of one of the two goods. With a slight abuse of notation, suppose that $\pi_{i}\left(p_{A}, p_{B} ; \sigma\right), i=A, B$ denotes profits before fixed costs. Consider the function

$$
\bar{F}(\sigma) \equiv\left\{F \mid \pi_{A}\left(p_{A}^{M}, p_{B}^{M} ; \sigma\right)+\pi_{B}\left(p_{A}^{M}, p_{B}^{M} ; \sigma\right)-2 F=\pi_{i}\left(p_{i}^{M} ; p_{j}=\infty, \sigma\right)-F\right\}
$$

with the obvious interpretation that if $F<\bar{F}(\sigma)$, then an investor controlling both firms would, as under Assumption (v), want to offer both commodities at symmetric monopoly profit maximizing prices $p_{A}^{M}=p_{B}^{M}$, whilst for $F>\bar{F}(\sigma)$, provided that production is profitable for at least one firm, she would liquidate one of the two firms and offer the product by the other firm $i$ at the single monopoly profit maximizing price $p_{i}^{M} . \bar{F}$ is decreasing in $\sigma$. At $\sigma=0$, we have $p_{i}^{M}=p_{A}^{2 M}=p_{B}^{M}$ and $\pi_{A}\left(p_{A}^{M}, p_{B}^{M} ; 0\right)=\pi_{B}\left(p_{A}^{M}, p_{B}^{M} ; 0\right)=\pi_{i}\left(p_{i}^{M}, \infty\right)$ so that $\bar{F}=\pi_{i}\left(p^{2 M}, p^{2 M} ; 0\right)$. At $\sigma=1$, one of the two production processes is superfluous, so that $\bar{F}=0$.

Assumption (v') states that we are in the regime where $F<\bar{F}(\sigma) .{ }^{10}$ We now formulate Corollaries to our Propositions 3 to 6. In the first the acquisition decisions are exactly the same, so the proofs are straightforward and omitted. For the last two corollaries, $I$ acquires minimal rather than maximal controlling stakes. We sketch the proofs for those.

Corollary 6.1: Let the remaining initial ownership in firm $A$ and the ownership of firm B be both dispersed, and Assumption (v') hold. Then investor I acquires a minimal indirect controlling stake in firm $B$ so that $\gamma^{*}=\hat{\alpha}_{B}$, and liquidates firm $B$.

CoRollary 6.2: Let the remaining initial ownership in firm A be concentrated and the ownership of firm B dispersed, and let Assumption (v') hold. Then the result of Corollary 6.1 obtains.

Corollary 6.3: Let the remaining initial ownership in firm A be dispersed and the ownership of firm B concentrated, and let Assumption ( $\left.v^{\prime}\right)$ hold. Then, I acquires the maximal direct controlling stake in firm B so that $\alpha_{B}^{*}=1$ and liquidates firm A.

\footnotetext{
${ }^{10}$ In the baseline model, we obviously were in the regime $F>\bar{F}(\sigma)$.
} 
Under Assumption ( $\mathrm{v}^{\prime}$ ) it is, by arguments analogous to the ones used in the proof to Proposition 5, always optimal for $I$ to buy firm $B$, and to shut down firm $A$.

COROLlary 6.4: Let the remaining initial ownership in firm A and the ownership of firm $B$ be both concentrated, and let Assumption (v') hold. Then I acquires a minimal indirect controlling stake in firm B so that $\gamma^{*}=\hat{\alpha}_{B}$ and liquidates firm B.

The proof of this last corollary is analogous to the one of Proposition 6 without shut down. I's overall payoff equals the sum of profits of both firms minus the outside options of the two block holders. From Corollary 6.3 we know that the outside option of $I_{A}$ is equal to zero in case he does not sell because then $A$ is shut down, so $I$ obtains all shares in $A$ at zero cost. $I$ therefore maximizes $\pi_{A}^{k}(\omega)-\pi_{B}^{k}(\omega)-\pi_{B}^{O}(0)$. The optimum with minimal transactions costs is thus achieved by a minimal indirect investment in firm $B$ so that $\gamma^{*}=\hat{\alpha}_{B}$ and a shut down of firm $B$.

\section{Related Literature}

Our paper is located at the interface between product market outcomes and acquisition decisions. We discuss first the related literature in corporate finance, and then in industrial economics. Turning first to the former literature, our paper obviously is related to Grossman and Hart (1980)'s classic. They point out that in the absence of the possibility to directly extract private benefits of control (as under dispersed ownership), there are no gains per se that stem from acquiring a stake in $B$. We extend this by showing that this results in the active investor's change of objective. She increases just the returns to shares already held in $A$, which can be seen as her private benefit of controlling $B$. As this benefit is decreasing in her investment in $B$, the investor acquires as few shares as necessary to gain control, and sets prices in $B$ so that profits in $A$ increase. This private benefit of control also compares to the situation studied by 
Burkart, Gromb, and Panunzi (1998), in which I can directly extract private benefits of control in $B$. It is similar to our case in that it will be optimal in the second stage of the game to extract the more private benefits, the lower her investment in $B$.

As to other, financially related reasons for ownership extending across firms, Hellwig (2000) emphasizes cross acquisitions as a takeover defense. ${ }^{11}$ Almeida and Wolfenzon (2006) focus on pyramiding that results from the cost saving indirect acquisition of new firms without external financing via the firm controlled by an investor, relative to the direct acquisition by that investor. Riyanto and Toolsema (2008) consider the possibility to shift resources from one firm into another, called tunneling, a phenomenon obviously arising in our model. Finally, Malueg (1992) and Gilo, Moshe, and Spiegel (2006) focus on passive investments in competitors as serving to facilitate tacit collusion. We cannot pursue this focus within our static model. Instead, we concentrate on endogenous acquisition decisions, which these authors do not consider.

Besides, there is a substantive empirical literature addressing ownership and control across firms (La Porta, Lopez-de Silanes, Shleifer, and Vishny, 1998; La Porta, Lopez-de Silanes, and Shleifer, 1999; Franks and Mayer, 2000; Faccio and Lang, 2002, e.g.). Unfortunately, product market outcomes are not studied in this literature, which is one of our main interests.

The most closely related paper to ours is Dorofeenko, Lang, Ritzberger, and Shorish (2008). They focus on how the combination of indirect and direct investments leads to control structures extending across firms. The product market is not modeled. Dorofeenko, Lang, Ritzberger, and Shorish then use German data to identify control scenarios consistent with the observed ownership structure around one German firm, Allianz. Moreover, they show that there is a high concentration of ultimate ownership of competing firms in Germany. Allen and Gale (2000) report similar phenomena for the U.S. Also, in setting the frame for his influential textbook on corporate finance, Tirole (2006) shows a high ownership share by non-financial firms.

Turning now to the related literature in industrial economics, O'Brien and Salop (2000) provide a very interesting discussion of the relevant economic and legal aspects. In a series of

\footnotetext{
${ }^{11}$ See Becht and Boehmer $(2001,2003)$ for descriptive evidence.
} 
papers, Charlety-Lepers, Fagart and Souam study acquisition decisions in an n-firm Cournot industry with homogeneous products ${ }^{12}$. In their most general version, one investor holds noncontrolling or controlling stakes in a subset of the other firms. Within a two stage game, they study that investor's acquisition of shares in one second firm, and its impact on the industry's quantities produced and sold. Their set up is thus quite similar to ours. It is more general in that they consider an arbitrary number of firms, albeit inactive in the market for acquisitions. Yet it is a special case in that involves a homogenous product economy.

It is well known that under Cournot competition involving homogenous products, the sum of two firms' profits is lower if they are jointly controlled, as compared to a situation in which they compete; and that outsiders of joint control or merger arrangements may benefit from those, whilst insiders do not. ${ }^{13}$ This feature of homogeneous product Cournot models tends to unduly bias the analysis of cross firm ownership arrangements. Indeed, as a direct consequence the controlling investor will always shut down the firm in which her stake is smaller. Thus, if our world were a homogeneous product Cournot one, $I$ would shut down firm $B$ if $\omega<1$, and firm $A$ if $\omega>1$. Paradoxically, she would eventually shut down the firm $A$ controlled by her even if she did not control firm $B$, but held a larger stake in it! ${ }^{14}$

By contrast, in our model with Bertrand competition in differentiated products, $I$ only has the incentive to shut down a competitor if it sells substitutes that are sufficiently close, relative to the fixed costs of operating the firm. This appears very plausible. In addition, we have shown the results to change drastically if the investor does not want to shut down the competitor, which is the case when the industry's market is substantively enlarged by the presence of a competing product - and the fixed costs of producing it are sufficiently low.

Foros, Kind, and Shaffer (2010), as we do, study the product market effects of acquisitions within a Bertrand framework. Yet they do not endogenize acquisition decisions. They study a

\footnotetext{
${ }^{12}$ Charléty-Lepers, Fagart, and Souam (2009) is the most recent one.

${ }^{13}$ The well known classic on this is Salant, Switzer, and Reynolds (1983). Variants of the argument are provided by Fudenberg and Tirole (1984), Deneckere and Davidson (1985), and Reitman (1994).

${ }^{14}$ This follows from Proposition 1 in Charléty-Lepers, Fagart, and Souam (2009).
} 
Hotelling model with three firms and find that the joint profits of two firms may be higher when the ownership arrangement is partial rather than full. We also derive this result in our two firm model which is otherwise more general. In fact, we extended a linear demand version of our model to three firms. While incorporating that third (passive) firm softens the magnitude of the effects, there is no qualitative change in our results.

Flath (1991) shows that in a Bertrand duopoly akin to the one discussed by us, firms may have an incentive to passively invest in rival firms if they are initially held by dispersed shareholders, a result that is part of our Proposition 1(iv), but has interesting consequences on the acquisition stage we draw in Proposition 3. ${ }^{15}$

A last related paper in the industrial economics literature is Brito, Cabral, and Vasconcelos (2010). They consider a situation in which $A$ holds a controlling stake in $B$ and characterize, among others, the effect of turning this into a non-controlling one. They find that it this increases consumer surplus. This is not surprising in view of our more encompassing results in Section 3.

\section{Concluding Remarks}

Within an institution free world involving two symmetric price setting firms, we develop a two stage game, with the first stage involving the non-controlling or controlling partial or full acquisition decisions of one active investor, and the second stage the two firms' resulting pricing decisions. The investor is assumed to initially hold controlling cash flow rights in one of the firms, and thus can either directly acquire shares in the competitor from her own funds, or induce the controlled firm to indirectly do so. The investor's acquisition decisions depend on

\footnotetext{
${ }^{15}$ There are also more remotely related results for Cournot industries. Reynolds and Snapp (1986), Farrell and Shapiro (1990), and Flath (1992) find that the effect of rivals owning shares in one another, either directly or indirectly, is that output is reduced. Flath (1991) asks the question when it is profitable for firms to invest in their rivals if they are initially all held by dispersed shareholders so that there is no financial gain from the acquisition per se. He finds that firms will never want to do that even though it would enhance total industry profits. The reason is that given the investments of the others a firm will always have an incentive to decrease its investments in its rivals. Clayton and Jorgensen (2005) characterize the respective optimal cross-holding positions in a Nash equilibrium sense, also allowing firms to take short positions in rivals.
} 
the structure of the remaining ownership in the firm controlled by her as on that of the competing firm; and on the resulting product market prices and profits.

We completely characterize both, the acquisition decisions and the resulting product market prices and profits, conditional upon the initial ownership structures of the two firms, in which we combine alternatives in which the remaining shares in the firm controlled by the active investor are held by very small owners vs. a block holder, with the same alternatives in the ownership structure of the competing firm.

Contrary to expectations that indirect acquisitions and complete monopolistic control are the preferred outcomes, we find that monopoly, if desired at all, does not necessarily result in full ownership. Also, the investor uses the indirect acquisition mode only in order to achieve the preferred product market allocation. By contrast, she prefers direct acquisitions whenever gains can be realized from the acquired shares per se.

In general, the outcomes of both the acquisition game and the ensuing pricing game in the product market depend very much on the initial distribution of ownership in the two firms. Going through four cases, we arrive at a number of detailed testable empirical predictions.

Our model setup could be challenged in many respects. To highlight a few: Firstly, our industry consists of two firms only, so the acquisition of control rights in the competing firm leads immediately to the monopolistic control of the entire industry. Secondly, one might argue that if controlling a firm, investors typically do not exercise control on prices, but only on strategic variables such as product quality, the size of the product portfolio, cost reducing investment, or indeed acquisitions. Thirdly, the acquisition of cash flow or control rights may be contested by competitors. Lastly, financial market considerations are neglected. To react to the latter claim, we neglect these two towards focussing on the interplay between product and acquisition markets.

Towards reacting to the first two limitations, we have analyzed a numerical version of the model, that involves three symmetric competing specialized firms, in which controlling block holders directly determine cost reducing investment rather than prices. The determination of the 
latter is left to an independent profit maximizing management. Surprisingly little changes in this substantively extended set up. All that happens is that the effects derived above are softened, due to both, the impact of competition from the outsider firm, and the less direct impact of the controlling owners. We claim that in view of this, the above analysis should carry through these generalizations.

A last limitation is that we do not allow for competition in the market for acquisitions. Accounting for this is clearly more involved. Yet a number of points derived in the present paper generalize. Note in particular that in the acquisition sub-game the results remain qualitatively the same if several investors compete to obtain shares in a firm owned by dispersed shareholders (as in our cases 1 and 2): As these shareholders are essentially non-pivotal, they claim the ex post value of their share, so investors are only interested in modifying the allocation decisions in order to increase the value of the shares already held. By a similar reason, these investors have no incentive to increase their share in firms already controlled by them, if the remaining shares are owned by shareholders who are non-pivotal for the acquisition of the other firm (as in our cases 1 and 2).

The outcomes of the acquisition sub-game will be qualitatively different from those derived in our cases 3 and 4, however, when the target is controlled by a pivotal block holder. This is so because raider competition shifts bargaining power to that block holder who then, just as non-pivotal shareholders, participates in the acquisition gains. Taking this to the extreme, raider competition may push the acquisition gains all to that block holder, which should result in outcomes not dissimilar to those derived for out cases 1 and 2. It will be interesting to study this more formally in future work. We see our paper as a first step towards this. 


\section{Appendix}

\section{Proof of Proposition 1}

(i) Comparing the respective necessary conditions for profit maximization and invoking Assumption (i) implying symmetry between the two profit functions, we obtain

$$
\frac{\partial \pi_{A}\left(p_{A}, p_{B}\right)}{\partial p_{A}}=-\omega \cdot \frac{\partial \pi_{B}\left(p_{A}, p_{B}\right)}{\partial p_{A}}<\frac{\partial \pi_{B}\left(p_{A}, p_{B}\right)}{\partial p_{B}}=0
$$

The first part of Assumption (iii) invoking strict concavity of $\pi_{A}$ in $p_{A}$ implies $p_{A}^{O}(\omega)>$ $p_{B}^{O}(\omega)$

(ii) It follows directly from the above argument and Assumption (i) that

$$
\pi_{A}\left(p_{A}^{O}(\omega), p_{B}^{O}(\omega)\right)<\pi_{B}\left(p_{A}^{O}(\omega), p_{B}^{O}(\omega)\right)
$$

for all $\omega>0$.

(iii) Differentiating totally the two necessary conditions and inverting the matrix of derivatives, we obtain

$$
\left[\begin{array}{c}
\frac{\partial p_{A}^{O}(\omega)}{\partial \omega} \\
\frac{\partial p_{B}^{O}(\omega)}{\partial \omega}
\end{array}\right]=\frac{-1}{a_{4} a_{1}-a_{3} a_{2}}\left[\begin{array}{cc}
a_{4} & -a_{3} \\
-a_{2} & a_{1}
\end{array}\right]\left[\begin{array}{c}
\frac{\partial \pi_{B}\left(p_{A}, p_{B}\right)}{\partial p_{A}} \\
0
\end{array}\right],
$$

so that we have to evaluate

$$
\frac{\partial p_{A}^{O}(\omega)}{\partial \omega}=\frac{-a_{4}}{a_{4} a_{1}-a_{3} a_{2}} \frac{\partial \pi_{B}\left(p_{A}, p_{B}\right)}{\partial p_{A}}
$$

and

$$
\frac{\partial p_{B}^{O}(\omega)}{\partial \omega}=\frac{a_{2}}{a_{4} a_{1}-a_{3} a_{2}} \frac{\partial \pi_{B}\left(p_{A}, p_{B}\right)}{\partial p_{A}},
$$


where

$$
a_{1} \equiv \frac{\partial^{2} \pi_{A}\left(p_{A}, p_{B}\right)}{\partial p_{A}^{2}}+\omega \frac{\partial^{2} \pi_{B}\left(p_{A}, p_{B}\right)}{\partial p_{A}^{2}}
$$

$$
\begin{gathered}
a_{2} \equiv \frac{\partial^{2} \pi_{B}\left(p_{A}, p_{B}\right)}{\partial p_{A} \partial p_{B}}, \\
a_{3} \equiv \frac{\partial^{2} \pi_{A}\left(p_{A}, p_{B}\right)}{\partial p_{A} \partial p_{B}}+\omega \frac{\partial^{2} \pi_{B}\left(p_{A}, p_{B}\right)}{\partial p_{A} \partial p_{B}},
\end{gathered}
$$

and

$$
a_{4} \equiv \frac{\partial^{2} \pi_{B}\left(p_{A}, p_{B}\right)}{\partial p_{B}^{2}}
$$

The denominator of the right hand fraction, $a_{4} a_{1}-a_{3} a_{2}$, is positive under Assumption (iv). Both numerators $-a_{4}$ and $a_{2}$ are positive under Assumptions (iii) and (iv). Using Assumption (ii), both (22) and (23) are positive.

Towards seeing that $\partial p_{A}^{O}(\omega) / \partial \omega>\partial p_{B}^{O}(\omega) / \partial \omega$, observe that $\partial p_{A}^{O}(\omega) / \partial \omega \gtrless \partial p_{B}^{O}(\omega) / \partial \omega$ iff $-a_{4} \gtrless a_{2}$. But $-a_{4}>a_{2}$ by the second part of Assumption (iv).

(iv) Differentiating $\pi_{A}\left(p_{A}^{O}(\omega), p_{B}^{O}(\omega)\right)$ and $\pi_{B}\left(p_{A}^{O}(\omega), p_{B}^{O}(\omega)\right)$, we obtain

$$
\frac{\partial \pi_{A}\left(p_{A}^{O}(\omega), p_{B}^{O}(\omega)\right)}{\partial \omega}=\frac{\partial \pi_{A}\left(p_{A}, p_{B}\right)}{\partial p_{A}} \frac{\partial p_{A}^{O}(\omega)}{\partial \omega}+\frac{\partial \pi_{A}\left(p_{A}, p_{B}\right)}{\partial p_{B}} \frac{\partial p_{B}}{\partial \omega}
$$

and

$$
\frac{\partial \pi_{B}\left(p_{A}^{O}(\omega), p_{B}^{O}(\omega)\right)}{\partial \omega}=\frac{\partial \pi_{B}\left(p_{A}, p_{B}\right)}{\partial p_{A}} \frac{\partial p_{A}}{\partial \omega}+\frac{\partial \pi_{B}\left(p_{A}, p_{B}\right)}{\partial p_{B}} \frac{\partial p_{B}^{O}(\omega)}{\partial \omega}
$$

In (28), $\partial \pi_{A}\left(p_{A}, p_{B}\right) / \partial p_{A} \rightarrow 0$ at $\left(p_{A}^{O}(\omega), p_{B}^{O}(\omega)\right)$ when $\omega \rightarrow 0$, so that the first term is 
close to zero in that neighborhood. The second term is strictly positive throughout, so that $\pi_{A}^{O}(\omega)$ increases up to some $\omega^{O}$. By the second part of Assumption (ii) and the second part of Part (iii) of Proposition 1, the negative first term must eventually dominate the positive second one as $\omega$ increases, so that $\partial \pi_{A}\left(p_{A}(\omega), p_{B}(\omega)\right) / \partial \omega<0$ for $\omega>\omega^{O}$.

In (29) the two components of the first term are positive by Assumption (ii) and Proposition 1 (ii), respectively, whilst the first component of the second term is zero by the necessary condition, so that $\partial \pi_{B}\left(p_{A}(\omega), p_{B}(\omega)\right) / \partial \omega \geq 0$ for all positive $\omega$.

\section{Proof of Proposition 2}

(i) Below, under (iii) we show that $p_{A}^{M}(\omega)$ strictly increases and $p_{B}^{M}(\omega)$ strictly decreases in $\omega$. By Assumption (i) we know that $p_{A}^{M}(\omega)=p_{B}^{M}(\omega)$ at $\omega=1$. To satisfy this equality, it must hold that $p_{A}^{M}(\omega)<p_{B}^{M}(\omega)$ for $\omega<1$ and $p_{A}^{M}(\omega)>p_{B}^{M}(\omega)$ for $\omega>1$.

(ii) Below, under (iv) we show that $\pi_{A}\left(p_{A}^{M}(\omega), p_{B}^{M}(\omega)\right)$ decreases and $\pi_{B}\left(p_{A}^{M}(\omega), p_{B}^{M}(\omega)\right)$ increases in $\omega$. By Assumption (i) we know that $\pi_{A}\left(p_{A}^{M}(\omega), p_{B}^{M}(\omega)\right)=\pi_{B}\left(p_{A}^{M}(\omega), p_{B}^{M}(\omega)\right)$ at $\omega=1$. To satisfy this equality, it must hold that $\pi_{A}\left(p_{A}^{M}(\omega), p_{B}^{M}(\omega)\right)>\pi_{B}\left(p_{A}^{M}(\omega), p_{B}^{M}(\omega)\right)$ for $\omega<1$ and $\pi_{A}\left(p_{A}^{M}(\omega), p_{B}^{M}(\omega)\right)<\pi_{B}\left(p_{A}^{M}(\omega), p_{B}^{M}(\omega)\right)$ for $\omega>1$.

(iii) Differentiating the two necessary conditions and inverting the matrix of derivatives, we obtain

$$
\left[\begin{array}{c}
\frac{\partial p_{A}^{M}(\omega)}{\partial \omega} \\
\frac{\partial p_{B}^{M}(\omega)}{\partial \omega}
\end{array}\right]=\frac{-1}{b_{4} b_{1}-b_{3} b_{2}}\left[\begin{array}{cc}
b_{4} & -b_{3} \\
-b_{2} & b_{1}
\end{array}\right] \begin{aligned}
& \frac{\partial \pi_{B}\left(p_{A}, p_{B}\right)}{\partial p_{A}} \\
& \frac{\partial \pi_{B}\left(p_{A}, p_{B}\right)}{\partial p_{B}}
\end{aligned}
$$

where

$$
b_{1} \equiv \frac{\partial^{2} \pi_{A}\left(p_{A}, p_{B}\right)}{\partial p_{A}^{2}}+\omega \frac{\partial^{2} \pi_{B}\left(p_{A}, p_{B}\right)}{\partial p_{A}^{2}},
$$


and

$$
b_{2}=b_{3} \equiv \frac{\partial^{2} \pi_{A}\left(p_{A}, p_{B}\right)}{\partial p_{A} \partial p_{B}}+\omega \frac{\partial^{2} \pi_{B}\left(p_{A}, p_{B}\right)}{\partial p_{A} \partial p_{B}}
$$

as well as

$$
b_{4} \equiv \frac{\partial^{2} \pi_{A}\left(p_{A}, p_{B}\right)}{\partial p_{B}^{2}}+\omega \frac{\partial^{2} \pi_{B}\left(p_{A}, p_{B}\right)}{\partial p_{B}^{2}}
$$

First, $b_{4} b_{1}-b_{3} b_{2}$ is strictly positive by the second order condition. Both numerators $-b_{4}$ and $b_{2}$ are positive by Assumptions (iii) and (iv). Hence, by Part(ii) of the Proposition, $\partial p_{A}^{M}(\omega) / \partial \omega>0$ and $\partial p_{B}^{M}(\omega) / \partial \omega<0$ if

$$
b_{4} \frac{\partial \pi_{B}\left(p_{A}, p_{B}\right)}{\partial p_{A}}-b_{3} \frac{\partial \pi_{B}\left(p_{A}, p_{B}\right)}{\partial p_{B}}<0
$$

and

$$
-b_{3} \frac{\partial \pi_{B}\left(p_{A}, p_{B}\right)}{\partial p_{A}}+b_{1} \frac{\partial \pi_{B}\left(p_{A}, p_{B}\right)}{\partial p_{B}}>0
$$

To ensure that the inequalities (34) and (35), respectively, hold, we need that both $\left|b_{4}\right|>b_{3}$ and $\left|b_{1}\right|>b_{3}$. By a proper manipulation of the second order conditions, it is easy to show that both inequalities are satisfied.

(iv) Differentiating $\pi_{A}\left(p_{A}^{M}(\omega), p_{B}^{M}(\omega)\right)$ and $\pi_{B}\left(p_{A}^{M}(\omega), p_{B}^{M}(\omega)\right)$,

$$
\frac{\partial \pi_{A}\left(p_{A}^{M}(\omega), p_{B}^{M}(\omega)\right)}{\partial \omega}=\frac{\partial \pi_{A}\left(p_{A}, p_{B}\right)}{\partial p_{A}} \frac{\partial p_{A}^{M}(\omega)}{\partial \omega}+\frac{\partial \pi_{A}\left(p_{A}, p_{B}\right)}{\partial p_{B}^{M}(\omega)} \frac{\partial p_{B}}{\partial \omega}
$$

and

$$
\frac{\partial \pi_{B}\left(p_{A}^{M}(\omega), p_{B}^{M}(\omega)\right)}{\partial \omega}=\frac{\partial \pi_{B}\left(p_{A}, p_{B}\right)}{\partial p_{A}} \frac{\partial p_{A}^{M}(\omega)}{\partial \omega}+\frac{\partial \pi_{B}\left(p_{A}, p_{B}\right)}{\partial p_{B}^{M}(\omega)} \frac{\partial p_{B}}{\partial \omega}
$$


we see that $\partial \pi_{A}\left(p_{A}(\omega), p_{B}(\omega)\right) / \partial \omega<0$ follows directly from the fact that $\partial \pi_{A}\left(p_{A}, p_{B}\right) / \partial p_{A}<$ 0 at $\left(p_{A}^{M}(\omega), p_{B}^{M}(\omega)\right)$, Assumption (i) and Proposition 2 (iii). $\partial \pi_{B}\left(p_{A}(\omega), p_{B}(\omega)\right) / \partial \omega>0$ follows from the symmetric argument.

\section{Proof of Proposition 3}

From Proposition 1(iv) we know that $\pi_{A}^{O}(\omega)$ increases for small $\omega$ and is maximized at $\omega^{O}$. By contrast, Proposition 2(iv) states that $\pi_{A}^{M}(\omega)$ is a strictly decreasing function, so that with full control, investor I's payoff is maximized by acquiring the minimal threshold volume $\hat{\alpha}_{B}$ of shares in firm $B$.

If there is an $\omega^{M} \in\left(0,1 / \alpha_{A}^{0}\right)$ with $\pi_{A}^{O}\left(\omega^{O}\right)=\pi_{A}^{M}\left(\omega^{M}\right)$, then it follows directly from the fact that $\pi_{A}^{M}(\omega)$ is strictly decreasing that if the minimal controlling stake $\hat{\alpha}_{B} \leq \alpha_{A}^{0} \omega^{M}$, then $\pi_{A}^{O}\left(\omega^{O}\right)=\pi_{A}^{M}\left(\omega^{M}\right)<\pi_{A}^{M}\left(\hat{\alpha}_{B}\right)$, so that $I$ prefers to acquire a controlling stake $\hat{\alpha}_{B}$ in $B$. By contrast, if $\hat{\alpha}_{B}>\alpha_{A}^{0} \omega^{M}$, then $I$ will prefer to acquire non-controlling cash flow rights in firm $B$ such that $\omega^{O}=\left(\alpha_{B}+\alpha_{A}^{0} \gamma\right) / \alpha_{A}^{0}$.

Towards determining the mode of acquisition, observe that the two alternative acquisition modes have differing allocation effects and thus are not payoff neutral. Acquiring minimal controlling shares $\hat{\alpha}_{B}$ directly costs $I \hat{\alpha}_{B}$, whilst indirect acquisition via firm $A$ costs her $\alpha_{A}^{0} \hat{\alpha}_{B}<$ $\hat{\alpha}_{B}$. Hence $I$ acquires the minimal controlling cash flow rights through firm $A$, so that $\gamma^{*}=$ $\omega^{k}, k=O, M$ and $\alpha_{B}^{*}=0$. Only if she would fully own firm $A$, i.e. $\alpha_{A}^{0}=1$, would she be indifferent between direct and indirect acquisition.

\section{Proof of Proposition 5}

First we show that for each $\omega$ it is optimal to set $\gamma^{*}=0$. Then we establish that choosing $\alpha_{A}^{*}=\alpha_{A}^{0}$ and $\alpha_{B}^{*}=1$ maximizes $I_{1}$ 's payoff.

Consider the second term of (17). For each $\omega$ investor $I$ wants to put maximal (respectively minimal) weight on $\left[\pi_{B}^{k}(\omega)-\pi_{B}^{O}(0)\right]$ if it is positive (respectively negative). The weight is given by $\left(\alpha_{B}+\alpha_{A}^{0} \gamma\right) /\left(\alpha_{B}+\gamma\right)$ and is maximized for any $\alpha_{B}>0$ whenever $\gamma=0$, and the maximum is 
1. It is minimized for any $\gamma>0$ whenever $\alpha_{B}=0$, and the minimum is $\alpha_{A}^{0}$.

First take the case in which $I$ does not control $B$. Then $\left[\pi_{B}^{O}(\omega)-\pi_{B}^{O}(0)\right] \geq 0$ for any $\omega \geq 0$ since $\pi_{B}^{O}(\omega)$ is strictly increasing in $\omega$ by Proposition 1 . This implies that in this case $\gamma=0$ is optimal.

Now take the case in which $I$ controls $B$. We will show that we have that $\left[\pi_{B}^{k}(\omega)-\pi_{B}^{O}(0)\right]>0$ for any optimal $\omega$ (notice that we do not need to show that this holds for values of $\omega$ for which (17) is not maximized). First, suppose $\omega=w$ is optimal and $\pi_{B}^{M}(w)-\pi_{B}^{O}(0) \geq 0$. Then we have that $\gamma=0$ is optimal. It remains to show that it is never optimal to choose $\omega=w$ such that $\pi_{B}^{M}(w)-\pi_{B}^{O}(0)<0$. We do this by contradiction. Suppose $\omega=w$ is optimal and $\pi_{B}^{M}(w)-\pi_{B}^{O}(0)<0$. Since $\pi_{B}^{M}(w)-\pi_{B}^{O}(0)<0$ it is optimal to set $\alpha_{B}=0$ and therefore (17) becomes

$$
\left.\Pi_{1}^{M}(w)\right|_{\alpha_{B}=0}=\alpha_{A}^{0} \pi_{A}^{M}(w)+\alpha_{A}^{0}\left[\pi_{B}^{M}(w)-\pi_{B}^{O}(0)\right] .
$$

By the principle of optimization, we have that $\pi_{B}^{M}(1)>\pi_{B}^{O}(0)$ because $\pi_{B}^{M}(1)$ results from maximizing the sum of profits by choosing $p_{A}$ and $p_{B}$, and $\pi_{B}^{O}(0)$ is the symmetric Nash equilibrium profit in $B$. Combining this with Proposition 2(ii) shows that $\pi_{B}^{M}(w)-\pi_{B}^{O}(0)<0$ implies $w<1$. But by Assumption (v) we have that $w=1$ maximizes (38), a contradiction.

From the above discussion it follows that it is always optimal to set $\gamma=0$ under control, because the optimal $\omega$ always satisfies $\left[\pi_{B}^{M}(\omega)-\pi_{B}^{O}(0)\right]>0$. Therefore, we can limit ourselves to

$$
\Pi_{1}^{k}(\omega)=\alpha_{A}^{0} \cdot \pi_{A}^{k}(\omega)+\left[\pi_{B}^{k}(\omega)-\pi_{B}^{O}(0)\right], k=O, M
$$

We now show that this is maximized at $\omega=1 / \alpha_{A}^{0}$, and that $I_{1}$ wishes to gain control in firm $B$. For this we use a revelation principle argument for $I_{1}$ 's payoff function in the monopoly case. Global optimality then follows by the principle of optimization. 
Maximizing $\Pi_{1}^{M}(\omega)$ in (39) is equivalent to solving

$$
\max _{p_{A}, p_{B}} \pi_{A}\left(p_{A}, p_{B}\right)+\frac{1}{\alpha_{A}^{0}} \pi_{B}\left(p_{A}, p_{B}\right) \quad \text { s.t. }\left(p_{A}, p_{B}\right) \in\left\{\left(p_{A}^{M}(\omega), p_{B}^{M}(\omega)\right) \mid \omega \in\left[\alpha_{A}^{0}, 1 / \alpha_{A}^{0}\right]\right\} .
$$

The objective function of (40) is identical to the objective function of (8) for $\omega=1 / \alpha_{A}^{0}$. Since we know that $\left(p_{A}^{M}\left(1 / \alpha_{A}^{0}\right), p_{B}^{M}\left(1 / \alpha_{A}^{0}\right)\right)$ is a maximizer of (8) for $\omega=1 / \alpha_{A}^{0}$, it is a maximizer of the unconstrained problem of (40) as well. $\left(p_{A}^{M}\left(1 / \alpha_{A}^{0}\right), p_{B}^{M}\left(1 / \alpha_{A}^{0}\right)\right)$ is also a maximizer of the constrained problem of (40) because it lies in the constraint set $\left\{\left(p_{A}^{M}(\omega), p_{B}^{M}(\omega)\right) \mid \omega \in\left[\alpha_{A}^{0}, 1 / \alpha_{A}^{0}\right]\right\}$. Therefore we get that $\omega=1 / \alpha_{A}^{0}$ is a maximizer of (39) for $k=M$. It is the unique maximizer by Proposition 2(iii). Finally, by the principle of optimization, the investor will choose control because in the oligopoly case additional constraints have to hold, namely that prices are equilibrium prices.

\section{References}

Allen, F., and D. Gale (2000): "Corporate Governance and Competition," in Corporate Governance: Theoretical and Empirical Perspectives, ed. by X. Vives, chap. 2, pp. 23-94. Cambridge University Press.

Almeida, H., and D. Wolfenzon (2006): "A Theory of Pyramidal Ownership and Family Business Groups," Journal of Finance, 61(6), 2637-2681.

Bagnoli, M., and B. L. Lipman (1988): "Successful Takeovers without Exclusion," The Review of Financial Studies, 1(1), 89-110.

Becht, M., and E. Boenmer (2001): "Ownership and Voting Power in Germany," in The Control of Corporate Europe, ed. by F. Barca, and M. Becht. Oxford University Press.

- (2003): "Voting control in German corporations," International Review of Law and Economics, 25(23), 1-29.

Brito, D., L. Cabral, and H. Vasconcelos (2010): "Duopoly Competition with Competitor Partial Ownership," Mimeograph, Universidade Nova de Lisboa, Lisbon, Portugal.

Burkart, M., D. Gromb, and F. Panunzi (1998): "Why Higher Takeover Premia Protect Minority Shareholders," The Journal of Political Economy, 106(1), 172-204.

Charléty-Lepers, P., M.-C. Fagart, and S. Souam (2009): "Incentives for Partial Acquisitions and Real Market Concentration," Journal of Institutional and Theoretical Economics, 165(3), 508-534.

Clayton, M. J., and B. N. Jorgensen (2005): "Optimal Cross Holding with Externalities and Strategic Interactions," Journal of Business, 78(4), 1505-1522.

Deneckere, R., ANd C. Davidson (1985): "Incentives to Form Coalitions with Bertrand Competition," RAND Journal of Economics, 16(4), 473-486.

Dorofeenko, V., L. H. P. Lang, K. Ritzberger, and J. Shorish (2008): “Who controls Allianz?,” Annals of Finance, 4, 75-103. 
Faccio, M., AND L. H. P. Lang (2002): "The Ultimate Ownership of Western European Corporations," Journal of Financial Economics, 65, 365395.

Farrell, J., AND C. Shapiro (1990): “Asset Ownership and Market Structure in Oligopoly," RAND Journal of Economics, 21(2), 275-292.

FLATH, D. (1991): "When is it rational for firms to acquire silent interests in rivals?," International Journal of Industrial Organization, 9(4), 573-583. $75-77$.

Foros, y., H. J. Kind, ANd G. Shaffer (2010): “Mergers and Partial Ownership,” CESifo Working Paper No. 2912, CESifo, Munich, Germany.

Franks, J., AND C. MAYER (2000): "Voting control in German corporations," ECGI Working Paper.

Fudenberg, D., and J. Tirole (1984): "The Fat-Cat Effect, the Puppy-Dog Ploy, and the Lean and Hungry Look," American Economic Review (Papers and Proceedings), 74(2), 361-366.

Gilo, D., Y. Moshe, and Y. Spiegel (2006): "Partial Cross Ownership and Tacit Collusion," RAND Journal of Economics, 37(1), 81-99.

Grossman, S. J., and O. D. Hart (1980): "Takeover Bids, The Free-Rider Problem, and the Theory of the Corporation," Bell Journal of Economics, 11(1), 42-64.

Hellwig, M. F. (2000): "On the Economics and Politics of Corporate Finance and Corporate Control," in Corporate Governance, ed. by X. Vives, chap. 3, pp. 95-134. Cambridge University Press.

Holmstrom, B., and B. Nalebuff (1992): "To the Raider Goes the Surplus? A Reexamination of the Free-Rider Problem," Journal of Economics and Management Strategy, 1(1), 37-62.

La Porta, R., F. Lopez-de Silanes, and A. Shleifer (1999): "Corporate Ownership around the World," Journal of Finance, 54, 471-517.

La Porta, R., F. Lopez-de Silanes, A. Shleifer, and R. W. Vishny (1998): “Law and Finance," The Journal of Political Economy, 106(6), 1113-1155.

Malueg, D. (1992): "Collusive Behavior and Partial Ownerships of Rivals," International Journal of Industrial Organization, (10), 27-34.

O’Brien, D. P., and S. C. Salop (2000): “Competition Effects of Partial Ownership: Financial Interest and Corporate Control," Antitrust Law Journal, 67, 559-610.

Rertman, D. (1994): "Partial Ownership Arrangements and the Potential for Collusion," Journal of Industrial Economics, 42(3), 313-322.

Reynolds, R. J., AND B. R. SNAPP (1986): "The competitive effects of partial equity interests and joint ventures," International Journal of Industrial Organization, 4(2), 141-153.

RitZBERGER, K. (2005): “Shareholder voting," Economics Letters, 86(1), 69-72.

Riyanto, Y. E., and L. A. Toolsema (2008): "Tunneling and Propping: A Justification for Pyramidal Ownership," Journal of Banking $\mathcal{F}$ Finance, 32(10), 2178-2187.

Röller, L.-H., and K. O. Stahl (2010): "Cash Flow Rights and Control in Vertically Related Industries," Working Paper, University of Mannheim, Mannheim, Germany.

Salant, S. W., S. Switzer, and R. J. Reynolds (1983): "Losses from Horizontal Merger: The Effects of an Exogenous Change in Industry Structure on Cournot-Nash Equilibrium," Quarterly Journal of Economics, 98(2), 185-199.

Tirole, J. (2006): The Theory of Coporate Finance. Princeton University Press. 